ISSN 1676-3742

\title{
Análise interpretativa acerca da relação existente entre a ordem cósmica e social no livro de Amós
}

\section{Interpretative analysis about of relationship between the cosmic and social order in the book of Amos}

\author{
Mariana do Nascimento Pernambuco
}

\section{Resumo}

Os textos doxológicos do livro de Amós (Am 4,13; 5,8-9; 9,5-6), por meio das descrições de alguns fenômenos naturais, apresentam a imagem de um Deus criador que está associada à imagem de um Deus destruidor, como forma de enfatizar sua soberania diante de todo o cosmo. Há também no livro, em três textos (Am 1,1; 8,8; e 9,1), a menção de um terremoto. Ao se entender sua relação com o restante do livro, mediante a crítica realizada pelo profeta à sociedade de Samaria, parece indicar-nos que, a partir do momento em que o ser humano rompe a ordem do direito e da justiça estabelecido por YHWH, este pode romper com a ordem cósmica. Isto aponta para o fato de que a relação estabelecida entre os seres humanos está intimamente associada a sua relação com Deus e com a natureza. Desse modo, a finalidade destas ameaças, considerado o conjunto do escrito, é que, por meio da mudança brusca realizada na natureza (como por exemplo, o terremoto), o povo de Israel reflita sua atual condição, se converta e restabeleça à ordem harmônica e justa na vida humana.

Palavras-chave: Bíblia e Ecologia; Doxologias no Antigo Testamento; Livro de Amós; Teologia Bíblica. 


\begin{abstract}
The doxological texts in the book of Amos (Am 4,13; 5,8-9; 9,5-6), through descriptions of the any natural phenomena, present the image of an God associated with the image of a destroyer God, as a way of stating His sovereignty face of entire the cosmos. Thete is also in the book, in three texts (Am 1,1; 8,8; and 9,1) the reference to the earthquake. To understand their relantionship with the rest of the book, by means of criticism made by prophet to society of Samaria, seems to indicate that at the moment that the human being disrupts the order of law and Justice established by YHWH, that YHWH can break the cosmic order. This indicates that the relation established between human beings is intimately associated their relation with God and with the nature. Thereby, the purpose these threats, considering the wide set of written, is that, sudden changes in nature (for example, the earthquarke), the people of Israel through their present condition, convert and restoring the harmonic order and righteous in human life.
\end{abstract}

Keywords: Bible and Ecology; Doxology in the Old Testament; Book of Amos; Biblical Theology.

\title{
Introdução
}

O livro de Amós inicia com a indicação de que sua profecia foi proferida "dois anos antes do terremoto" (Am 1,1). Tal terremoto parece atestado por resquícios arqueológicos. A menção explícita ao terremoto volta na última visão do profeta $(9,1)$, que conclui o ciclo das visões (c.7-9) e se encontra praticamente no final do livro. Alusões ao mesmo cataclisma podem ser detectadas no decorrer do livro, como por exemplo, em 8,8. De outro lado, o livro de Amós apresenta três textos doxológicos: 4,13; 5,8-9 e 9,5-6. Tais textos encontram-se separados no livro, mas apresentam evidentes pontos de contanto entre si. Estes textos enfatizam o poder de YHWH diante de todo o cosmo e como o cosmo está sob seu domínio. Diante disso, vê-se uma possível relação destas doxologias com as menções do terremoto no livro. Esta imagem de Deus delineada nas doxologias possui grande valor para se entender sua relação com os fenômenos naturais e se compreender a importância da menção do terremoto para a mensagem global do livro. 


\section{As doxologias do livro de Amós}

\subsection{A relação entre Am 4,13; 5,8-9 e 9,5-6}

Num primeiro olhar, estes textos presentes no livro parecem "estranhos" dentro de seu contexto e entorno. Retirados do lugar que ocupam não perdem sua lógica textual. Contudo, parecem estar ligados, particularmente, ao contexto precedente, tornando-os importantes para a mensagem dos respectivos contextos que ocupam. Dentre as diversas possibilidades de gêneros literários, a que melhor se encaixa nos versículos é o gênero doxologia.

As doxologias são hinos cuja função primordial é exaltar o glorioso poder de YHWH por meio das obras de sua criação, seja por meio de fenômenos naturais, seja por meio da história humana. ${ }^{1}$ Dentro de um ambiente cúltico, em liturgias penitenciais, assumem a função de "doxologia do juízo" (devido ao fato de estarem inseridos em um contexto de punição e/ou lamentação). Assim, tais doxologias ressaltariam que os desastres ocorridos, por meio do juízo divino, com o povo, provinham de sua própria culpa. Contudo, seu objetivo não seria recordar a desgraça, mas ser um louvor pelo poder Criador de YHWH e visaria a exortar o povo que voltasse, através de uma vivência em que transparecesem as normas éticas e morais, para o único Senhor: YHWH. ${ }^{2}$ Tais doxologias teriam como uma de suas características marcantes o uso de refrões repetitivos ou de "assinaturas" que reforçassem a identificação de YHWH dentro do contexto criacional, para realçar o impacto dos textos sobre os seus ouvintes em vista do clímax das unidades textuais, como por exemplo "YHWH, Deus dos exércitos é o seu nome" e/ou "YHWH é o seu nome"."

Alguns autores chegam a afirmar que essas doxologias fariam parte de um úncio hino que foi fragmentado e inserido em diferentes partes do livro. Entretanto, um fator que colocaria em dúvida tal teoria seria o seu vocabulário. O vocabulário das doxologias é idêntico, em sua grande maioria, ao utilizado no livro de Amós. Tal semelhança verbal impediria que as doxologias fossem

\footnotetext{
${ }^{1}$ Cf. ABREGO DE LACY, J. M. Os livros proféticos. São Paulo: Ave-Maria, 1998, pp.66-67.

${ }^{2}$ Jeremias afirma que, devido ao seu contexto imediato, as doxologias inserem novo significado para a atualização da interpretação do livro dentro de uma nova realidade (Cf. JEREMIAS, J. Amos. Brescia: Paidéia Edritice, 2000, pp.20 e 103); BYARGEON, R. W. The Doxologies of Amos: a Study of Their Structure and Theology. Theological Educator 52 (1995), p.56.

${ }^{3}$ Cf. SWEENEY, M. A. The Twelve Prophets. Vol.1: Hosea, Joel, Amos, Obadiah, Jonah. A. Michael Glazier Book: Collegeville, MN: Liturgical Press, 200, p.228; HUBBARD, D. A. Joel e Amós: Introdução e Comentário. São Paulo: Vida Nova, 1996, p.120.
} 
um único hino que, posteriormente, teria sido fragmentado e inserido dentro do livro. A questão que se levanta, contudo, é que se essas doxologias fazem parte de um mesmo hino, não se explica bem o motivo pelo qual teriam sido divididas, separadas e inseridas em diferentes partes do livro. ${ }^{4}$

O estudo dos textos de Am 4,13; 5,8-9; e 9,5-6 mostra que eles apresentam vários pontos de contato entre si. Em primeiro lugar, a temática. Em todo o livro de Amós estas serão as únicas partes que desenvolvem esta imagem de Deus como ordenador de todo cosmo. Apesar de em todo o livro aparecer, de forma implícita, a imagem de um Deus que tem o poder sobre toda a criação (pois pode tanto mandar pragas como influenciar na história de seu povo ou de outros povos por meio de guerras), não se expressa tal confissão de modo tão explícito como aparece nos textos doxológicos. $\mathrm{O}$ vocabulário semelhante entre os textos doxológicos é outro fator que nos aponta para uma relação entre eles (tal como a utilização dos verbos no particípio e os títulos de YHWH). ${ }^{5}$

Esse mesmo vocabulário é muito similar ao vocabulário utilizado ao Deutero-Isaías, Jeremias, Jó (sendo esses livros de período mais recente, ou seja, posteriores à época de atuação do profeta Amós) e nos primeiros capítulos de Gênesis (como por exemplo: Is 43,1.7.12.15; 44,8; 45,7.8.12.18.19; Jr 49,23; 51,42.64; Jó 9,8.9; 10,22.25; 38,31; e Gn 1) ${ }^{6}$, assim como sua afinidade com textos que fazem alusão ao contexto criador de YHWH, como por exemplo Is 48,13. ${ }^{7}$ Sendo assim, as doxologias do livro de Amós poderiam fazer parte do mesmo período histórico, seguindo o mesmo estilo literário, muito similar ao utilizado dentro do culto. Tais correspondências, especialmente com o Deutero-Isaías e com Jeremias, além das descrições teofânicas

\footnotetext{
${ }^{4}$ Cf. ABREGO DE LACY, J. M. Os livros proféticos, pp.66-67.

${ }^{5}$ Cf. HAYES, K. M. The Mourning Earth (Amos 1:2) and the God Who Is. Word \& World 28/2 (2008), p.148; PAAS, S. Seeing and Singing: Visions and Hymns in the Book of Amos. Vetus Testamentum 52 (2002), p.255.

${ }^{6}$ Cf. FORESTI, F. Funzione semantica dei brani participiali di Amos: 4,13; 5,8s; 9,5s. Biblica 62 (1981), p.184. Segundo Fretheim, nesta perspectiva de YHWH como criador, Is 45,7s assim como Jr 29,10-11, falam da criação como salvação (FRETHEIM, T. E. Creation Untamed: The Bible, God, and Natural Disasters. Theological Exploration for the Church Catholic; Grand Rapids, Ml: Baker Academic, 2010, pp.99-100). Segundo Peterson, a idéia da criação já existia no período pré-exílico, mas só será melhor trabalhada e desenvolvida em época tardia, principalmente no Deutero-Isaías, em meados do VI século a.C. (PETERSON, D. L., "The Word of Creation on the Book of the Twelve". In: BROWN, W. P., MCBRIDE JR., S. D. (eds.)., God Who Creates: Essays in Honor of W. Sibley Towner. Grand Rapids, Ml/Cambridge, U.K.: Eerdmans, 2000, p.214).

${ }^{7}$ Cf. VON RAD, G. Teologia do Antigo Testamento. Vol.1 e 2. São Paulo: ASTE/TARGUMIM, 2006, p. 142 .
} 
(assim como os pronunciamentos de anúncio do nome de YHWH, muito comum nos escritos sacerdotais), ${ }^{8}$ levariam a crer que a datação mais provável seja, no mínimo, o tempo do exílio, podendo chegar ao pós-exílio imediato. Portanto, sua autenticidade é posta seriamente em dúvida por parecer interromper o contexto no qual estão localizadas, por uma teologia de Deus criador muito desenvolvida após o período da atividade do profeta Amós (cf. Is 54,110 ; Jr 31,35s), por sua visão cosmológica, e pela utilização de termos que são mais frequentes em períodos tardios. ${ }^{9}$

\subsection{Os textos no conjunto do livro}

Compreendendo as doxologias, dentro da visão tripartida do livro, os textos doxológicos de Am 4,13 e Am 5,8-9 encontram-se inseridos no bloco que trata dos oráculos contra Israel, que compreende os capítulos 3-6, considerados, por alguns autores, o centro de todo o livro. Nesta seção, o capítulo 4 fornece certa ênfase na punição proferida por YHWH que tem como consequência a destruição do povo, enquanto que o capítulo 5 expressa uma reação do profeta à sentença de condenação. ${ }^{10} \mathrm{Já}$ Am 9,5-6, está inserido no bloco das visões de Amós (7-9), formando o apêndice da quinta visão, que pode ser entendida como o ápice das demais, por seu aspecto de punição sobre toda a obra criada, seja de ordem cósmica, seja de ordem humana. ${ }^{11}$

Desse modo, tendo em vista que Am 4,1-3 e 4-5 trabalham outros temas (crítica social e crítica ao culto, respectivamente), a unidade textual que deve ser considerada é Am 4,6-13, em que o v.13 pode ser entendido como o ápice de sua unidade textual. Ou seja, o v.13 é independente redacionalmente, mas, no texto atual do livro, relaciona-se com o contexto precedente. ${ }^{12}$

\footnotetext{
${ }^{8}$ Cf. HAYES, K. M. The Mourning Earth (Amos 1:2) and the God Who Is. $W \& W 28 / 2$ (2008), pp.143-144.

${ }^{9}$ Cf. JEREMIAS, J. Amós, p.104; ZENGER, E. O livro de Amós. In: Introdução ao Antigo Testamento. São Paulo: Loyola, 2003, p.488; BALLARINI, T., VIRGULIN, S., LYONNET, S., Introdução à Bíblia: com antologia profética. Vol.2. Petrópolis, RJ: Vozes, 1978, p.26.

${ }^{10}$ Cf. ZENGER, E. O livro de Amós. In: Introdução ao Antigo Testamento, p.483.

${ }^{11}$ Cf. SICRE DIAZ, J. L. Profetismo em Israel: o profeta, os profetas, a mensagem. Petrópolis, RJ: Vozes, 1996, pp.248-249; SCHWANTES, M. "A Terra não pode suportar suas palavras" (Am 7,10): reflexão e estudo sobre Amós. São Paulo: Paulinas, 2004, p.34.

${ }^{12}$ Cf. SWEENEY, M. A. The Twelve Prophets. Vol.1: Hosea, Joel, Amos, Obadiah, Jonah, p.230; ALONSO SCHÖKEL, L.. SICRE DIAZ, J. L. Profetas. Vol.2. São Paulo: Paulinas, 1991, p.1005.
} 
Já Am 5,8-9 está inserida na unidade textual de Am 5,1-17 já que, no v.1, há a introdução de uma lamentação que estabelece um inquérito contra $\mathrm{o}$ povo. Os vv.16-17 seriam a setença deste inquérito estabelecido por YHWH contra o povo. Os vv.8-9 seriam o centro da ameaça por identificar quem é o juiz que colocará a sentença em prática. Interessante notar a intrínseca relação existente entre a ordem social e a ordem cósmica. ${ }^{13}$ Assim como 4,13, Am 5,8-9, apesar de ser independente redacionalmente, relaciona-se ao contexto no qual está inserido.

A unidade textual de Am 9,5-6 seria Am 9,1-6, tendo em vista que os vv. 5-6 podem ser compreendidos como um epílogo, apêndice ou, até mesmo, uma explicação da quinta visão em 9,1-4. Seu objetivo seria fornecer uma reflexão teológica à mesma por meio da imagem teofânica, além de reforçar a ameaça descrita na quinta visão, utilizando, inclusive, o mesmo vocabulário da visão para indicar a inevitabilidade do castigo. ${ }^{14}$ Logo, assim como as demais doxologias, está conectada ao contexto precedente.

${ }^{13}$ Cf. MCCOMISKEY, T. E. The Minor Prophets: An Exegetical and Expository Commentary. Vol.1: Hosea, Joel and Amos, Baker Book House: Grand Rapids, Michigan 49516, pp.334 e 419; ALONSO SCHÖKEL, L., SICRE DIAZ, J. L. Profetas. Vol.2, p.1005; ZENGER, E. O livro de Amós. In: Introdução ao Antigo Testamento, pp.484 e 488; BOVATI, P., MEYNET, R. Il Libro del Profeta Amos. Roma: Edizione Dehoniane, 1995, pp.175, 183, 186-187 e 191; JEREMIAS, J. Amos, pp.110-113; WOLFF, H. W. La Hora de Amós. Salamanca: Ediciones Sígueme, 1984, p.192; ASURMENDI, J. Amós e Oséias. São Paulo: Paulinas, 1992, p.24; HUBBARD, D. A. Joel e Amós: Introdução e Comentário, pp.184-185; BYARGEON, R. W. The Doxologies of Amos: a Study of Their Structure and Theology. TheoEdu 52 (1995), pp.5354; HASEL, G. F. Understanding the Book of Amos: Basic Issues in Current Interpretations. Grand Rapids: Baker, 1991, p.87; FORESTI, F. Funzione semantica dei brani participiali di Amos: 4,13; 5,8s; 9,5s. Bib 62 (1981), pp.181-182; WAARD, J. The Chiastic Structure of Amos V 1-17. Vetus Testamentum 27 (1977), pp.170-177.

${ }^{14}$ Cf. ALONSO SCHÖKEL, L., SICRE DIAZ, J. L. Profetas. Vol.2, p.1020; ZENGER, E. O livro de Amós. In: Introdução ao Antigo Testamento, pp.485-486 e 488; PAUL, S. M., Amos: a Commentary on the Book of Amos. Minneapolis: Fortress Press, 1991, pp.153 e 273-281; JEREMIAS, J. Amos, pp.200-209; WOLFF, H. W. La Hora de Amós, p.199; ABREGO DE LACY, J. M. Os livros proféticos, pp.67-68 (este indica que tal unidade coloca perante Israel o aspecto negativo da eleição); HUBBARD, D. A. Joel e Amós: Introdução e Comentário, pp.154-156; אגדת in Am 9,6. Biblica 82 (2001), p.93; BYARGEON, R. W. The Doxologies of Amos: a Study of Their Structure and Theology. TheoEdu 52 (1995), pp.51-53; FORESTI, F. Funzione semantica dei brani participiali di Amos: 4,13; 5,8s; 9,5s. Bib 62 (1981), p.182; ANDRADE, A. C. Am 9,1-4: A dimensão do juízo anunciado e sua motivações à luz de Am 7,1-8,14. Rio de Janeiro: PUC, Departamento de Teologia, Dissertação de Mestrado, 2003, p.36. 


\section{Análise dos textos doxológicos}

2.1. Am 4,13

\begin{tabular}{|c|c|c|c|}
\hline $4,13 \mathrm{a}$ & 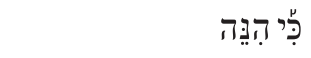 & Porque eis & Introdução \\
\hline $\mathrm{b}$ & יוֹצֵר הָרְים & aquele que forma os montes, & \multirow{2}{*}{ A } \\
\hline c & 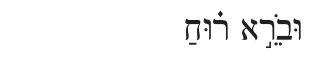 & cria o vento & \\
\hline $\mathrm{d}$ & 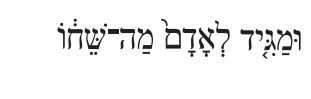 & $\begin{array}{l}\text { e revela ao homem qual } \\
\text { o seu pensamento. }\end{array}$ & B \\
\hline $\mathrm{e}$ & 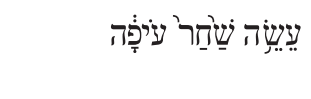 & $\begin{array}{l}\text { Aquele que faz da aurora } \\
\text { escuridão }\end{array}$ & \multirow{2}{*}{$A^{\prime}$} \\
\hline $\mathrm{f}$ & 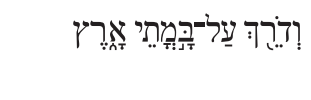 & $\begin{array}{l}\text { e caminha sobre as alturas } \\
\text { da terra: }\end{array}$ & \\
\hline $\mathrm{g}$ & 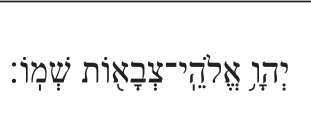 & $\begin{array}{l}\text { YHWH, Deus dos exércitos, } \\
\text { é o seu nome. }\end{array}$ & Conclusão \\
\hline
\end{tabular}

O v.13a introduz, por meio de um chamado à atenção, um personagem que não é nomeado. Segue-se então uma caracterização de seus feitos, onde pode ser identificada uma correspondência entre as subseções b-c/e-f. Ambas tratam do tema a cerca da natureza onde, o primeiro (A) mostra a relação deste personagem, não identificado, com a natureza, por meio da ação criadora em formar os montes e criar o vento; e o segundo (A') aponta para sua ação sobre a natureza e seu domínio sobre ela, afirmando que este faz da aurora escuridão e caminha sobre as alturas da terra.

O centro da doxologia encontra-se em 13d. Sua ênfase destaca-se por não utilizar os elementos mencionados em $\mathrm{A}$ e $\mathrm{A}^{\prime}$, mas inserir um elemento novo: o relacionamento deste personagem, ainda não identificado, com o ser humano. Este relacionamento se dá pelo fato de ser tal personagem o responsável por comunicar ao ser humano o seu pensamento.

Tal identificação atingirá seu auge na conclusão do versículo $13 \mathrm{~g}$, em que, após as descrições de poder, identifica seu sujeito: YHWH dos Exércitos. Este é, portanto, o ponto de chegada, o clímax, que é expresso em tom solene. 
A titulação de YHWH na conclusão do versículo está intrinsecamente relacionada às demostrações de poder desse Deus que perpassa toda a história, não só de seu povo, mas de todos os povos da terra, conforme o próprio livro apresenta (cf. Am 9,7). Logo, tal nomeação implica o dado de fé que consiste no impacto da presença de YHWH por seus feitos, seu poder e glória, seja por meio da salvação, seja pelo contexto de condenação. ${ }^{15}$

Neste versículo, então, parece haver uma progressão da descrição dos atos poderosos de Deus: primeiro o relaciona à criação, depois ao ser humano, em seguida à sua ação sobre a natureza e, por último, mostra seu domínio sobre todo o cosmo que, na descrição teofânica, assume certo tom punitivo. ${ }^{16}$ Todas essas atividades de YHWH culminam com sua identificação no final do v.13: "YHWH, Deus dos exércitos é o seu nome". ${ }^{17}$

\subsection{Am 5,8-9}

\begin{tabular}{|c|c|c|c|}
\hline $5,8 \mathrm{a}$ & 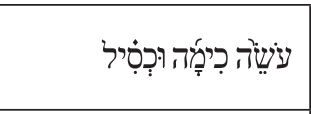 & $\begin{array}{l}\text { Aquele que faz as Plêiades } \\
\text { e Órion, }\end{array}$ & \multirow{5}{*}{$\begin{array}{l}\text { Relação com } \\
\text { a natureza }\end{array}$} \\
\hline $\mathrm{b}$ & 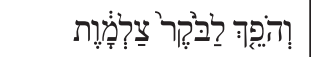 & e converte em manhã trevas & \\
\hline c & 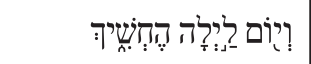 & e dia em noite obscurece. & \\
\hline $\mathrm{d}$ & 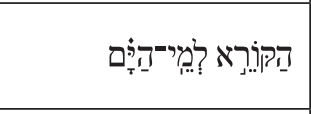 & $\begin{array}{l}\text { Aquele que chama pelas } \\
\text { águas do mar }\end{array}$ & \\
\hline $\mathrm{e}$ & 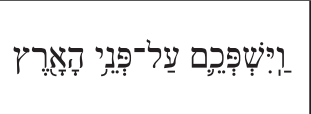 & $\begin{array}{l}\text { e as derrama sobre a face } \\
\text { da terra: }\end{array}$ & \\
\hline $\mathrm{f}$ & 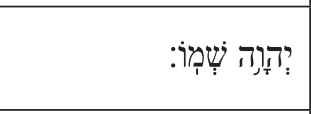 & YHWH é o seu nome. & $\begin{array}{c}\text { Identificação } \\
\text { do personagem }\end{array}$ \\
\hline $5,9 a$ & 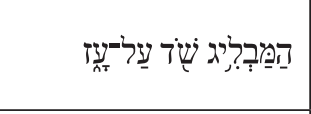 & $\begin{array}{l}\text { Aquele que lança destruição } \\
\text { sobre o forte }\end{array}$ & \multirow{2}{*}{$\begin{array}{l}\text { Relação com } \\
\text { a história }\end{array}$} \\
\hline $\mathrm{b}$ & 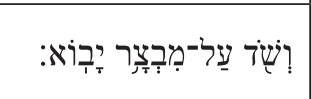 & $\begin{array}{l}\text { e destruição sobre } \\
\text { a fortificação vem. }\end{array}$ & \\
\hline
\end{tabular}

${ }^{15}$ Cf. JEREMIAS, J. Amos, pp.106-107; EICHRODT, W. Teologia do Antigo Testamento. São Paulo: Hagnos, 2004, pp.162 e 165.

${ }^{16}$ Cf. FORESTI, F. Funzione semantica dei Brani Participiali di Am 4,13; 5,8s; 9,5s. Bib 62 (1981), pp.180-181.

${ }^{17}$ Cf. SIMIAN-YOFRE, H. Amos: Nueva Versione, Introduzione e Commento. Milan: Paoline, 2002, p.90. 
Assim como Am 4,13, Am 5,8-9 está marcado pelo uso dos verbos no particípio que apresentam características do poder de Deus. Ao todo são quatro (três em 5,8 e um em 5,9). Todos estão interligados por um mesmo objetivo: ressaltar a atividade criadora de Deus por meio de sua obra e sua ação destrutiva sobre as obras humanas. ${ }^{18} \mathrm{O}$ texto inicia-se com dois particípios que caracterizam um personagem que só mais adiante é identificado. Os dois particípios iniciais estão ligados a termos do âmbito da natureza. Ao segundo particípio segue-se uma ação deste personagem (8c), que mostra o poder afirmado em 8 b. Identifica-se, então, um jogo duplo de palavras entre dia $\mathrm{x}$ noite e dia $\mathrm{x}$ noite.

O terceiro particípio, assim como o segundo, é seguido por uma ação deste personagem, ainda desconhecido, sobre a natureza. Desse modo, atinge seu clímax ao identificar nominalmente o personagem que está sendo exaltado por seus atos: "YHWH é o seu nome". Após a descrição do personagem por meio de sua relação com a natureza e de tê-lo identificado nominalmente, segue-se o quarto particípio que, unido a elementos bélicos, mostra a ação de YHWH sobre a história humana. Desse modo, a caracterização do personagem, seja por meio de sua relação com a natureza, seja em relação à história humana, atinge o seu clímax na sua identificação: "YHWH é o seu nome". Seria como que uma forma de apresentar aos destinatários do livro que Deus intervém não só nas ações naturais e na ordem cósmica, mas também na história humana e que, as proteções humanas nada são diante do poder onipotente de YHWH criador. Logo, dos quatro particípios que marcam a doxologia, três descrevem catástrofes. ${ }^{19}$

Assim como em 4,13, a perícope 5,8-9 descreve características do Deus criador através da exemplificação dos seus atos poderosos e atinge o seu ponto alto na sua identificação: יהוָוָה שְׁמו:, que mostra que o seu poder está acima

\footnotetext{
${ }^{18}$ Cf. ALONSO SCHÖKEL, L. Dicionário Bíblico Hebraico-Português. São Paulo: Paulus, 1997, pp.290 e 116-117; BOVATI, P., MEYNET, R. Il Libro del Profeta Amos, pp.182-183 (sendo as três catástrofes: trevas, inundação e destruição). Segundo Sweeney, esta é uma forma de convencer os ouvintes a retornarem a YHWH (SWEENEY, M. A. The Twelve Prophets. Vol.1: Hosea, Joel, Amos, Obadiah, Jonah, p.235).

${ }^{19}$ Cf. ALONSO SCHÖKEL, L. Dicionário Bíblico Hebraico-Português, pp.290 e 116-117; BOVATI, P., MEYNET, R. Il Libro del Profeta Amos, p.182 (sendo as três catástrofes: trevas, inundação e destruição). SWEENEY, M. A. The Twelve Prophets. Vol.1: Hosea, Joel, Amos, Obadiah, Jonah, p.235; BOVATI, P., MEYNET, R. Il Libro del Profeta Amos, p.183.
} 
de qualquer poder humano, seja em contexto de criação seja em contexto de destruição. ${ }^{20}$

\subsection{Am $9,5-6$}

\begin{tabular}{|c|c|c|c|}
\hline $9,5 \mathrm{a}$ & 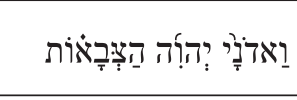 & $\begin{array}{l}\text { Pois Adonai (é) YHWH dos } \\
\text { Exércitos: }\end{array}$ & Identificação \\
\hline $\mathrm{b}$ & 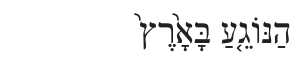 & aquele que toca na terra & \multirow{5}{*}{ Terra } \\
\hline c & וַתָּמוֹג & e ela estremece. & \\
\hline d & 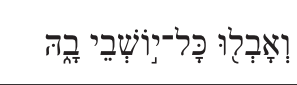 & $\begin{array}{l}\text { E se lamentam todos aqueles } \\
\text { que a habitam. }\end{array}$ & \\
\hline e & 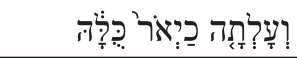 & Ela sobe como o Nilo toda ela & \\
\hline $\mathrm{f}$ & 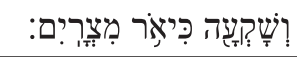 & e abaixa como o Nilo do Egito. & \\
\hline $9,6 \mathrm{a}$ & 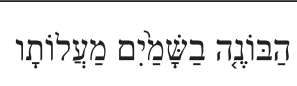 & $\begin{array}{l}\text { Aquele que constrói nos céus } \\
\text { suas escadas e }\end{array}$ & \multirow{2}{*}{ Céus } \\
\hline $\mathrm{b}$ & 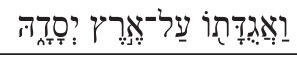 & sua abóboda sobre a terra alicerça. & \\
\hline c & 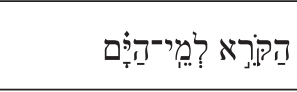 & $\begin{array}{l}\text { Aquele que chama pelas águas } \\
\text { do mar e }\end{array}$ & \multirow{2}{*}{ Águas do mar } \\
\hline d & 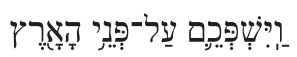 & as derrama sobre a face da terra: & \\
\hline $\mathrm{e}$ & 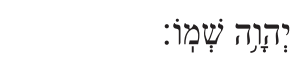 & YHWH é o seu nome. & Identificação \\
\hline
\end{tabular}

Todo o desenvolvimento dos versículos, que iniciam com uma identificação em Am 9,5, os levam a afirmação final expressa com semelhante titulação divina. Assim, o encerramento do versículo, em 9,6e, que fecha a doxologia com a identificação do personagem, pode ser compreendido como uma moldura, tendo em vista que a doxologia inicia, também, com uma iden-

${ }^{20}$ PAAS, S. Seeing and Singing: Visions and Hymns in the Book of Amos. VT 52 (2002), p.259; BRAMER, S. J. The Analysis of the Structure of Amos. Bibliotheca Sacra 156 (1999), p.173; BYARGEON, R. W. The Doxologies of Amos: a Study of Their Structure and Theology. TheoEdu 52 (1995), p.54; DEMPSTER, S. The Lord is His Name: a Study of the Distribuition of the Names and Titles of God in the Book of Amos. Revue Biblique 98 (1991), p.184; FORESTI, F. Funzione semantica dei brani participiali di Amos: 4,13; 5,8s; 9,5s. Bib 62 (1981), p.182. Segundo PAUL, S. M. Amos: a Commentary on the Book of Amos, pp.169-170, provavelmente o v.9 viria antes do v.8 e que, devido à destruição anunciada, foi transposto para depois do v.8 ou que a identificação de YHWH deve ser transposta para o final do v.9. Segundo J. Jeremias será na identificação de YHWH que se expressa a sua unicidade (JEREMIAS, J. Amós, p.122). 
tificação do personagem em 9,5a. ${ }^{21}$ Desse modo, vê-se que toda a doxologia visa a caracterizar a Deus: sua identificação ocupa os extremos e o seu centro indica o estabelecimento da morada de Deus nos céus, o que enfatiza seu domínio e poder sobre toda a criação, em um jogo de alto e baixo / alto e profundo: terra, céu e águas.

Logo, a imagem da doxologia de Am 9,5-6, alude às imagens do terremoto, da cheia do Nilo e de inundações sobre a terra, onde tais fenômenos naturais são determinantes aos seres vivos, seja no âmbito da vida (pois os seres vivos necessitam da água e da terra para sua sobrevivência) seja no âmbito da morte (os desastres naturais). As descrições dos abalos cósmicos e dos cataclismas são imagens típicas de descrições teofânicas, que indicam a presença e a onipotência de Deus e sua intervenção em escala cósmica, sejam elas geradoras de vida ou destrutivas, e que são interpretadas como sua revelação dentro da história humana. ${ }^{22}$

Na conclusão da doxologia, novamente a afirmação do nome da divindade, de forma simplificada ("YHWH é o seu nome"), como que a ressaltar todas as declarações sobre o poder de $\mathrm{YHWH}$, sua majestade e glória. ${ }^{23} \mathrm{~A}$ doxologia de Am 9,5-6 possui vocabulário semelhante ao da doxologia de Am 5,8 e ao do oráculo de Am 8,8. ${ }^{24}$

Desse modo, qual seria a função destas doxologias dentro de suas unidades textuais?

${ }^{21}$ Cf. ALONSO SCHÖKEL, L., SICRE DIAZ, J. L. Profetas. Vol.2, p.1023; SWEENEY, M. A. The Twelve Prophets. Vol.1: Hosea, Joel, Amos, Obadiah, p.270-271; SIMIAN-YOFRE, H. Amos: Nueva Versione, Introduzione e Commento, p.177; JARAMILLO RIVAS, P., “Amós”. In: Comissão Editorial Santiago Guijarro Oporto e Miguel Salvador García. Comentário ao Antigo Testamento. Vol.2. São Paulo: Ave Maria, 2004, p.333; BARRÉ, M. L. “Amós”. In: Novo Comentário Bíblico São Jerônimo: Antigo Testamento. São Paulo: Academia Cristã Ltda., Paulus, 2007, p.448; HUBBARD, D. A. Joel e Amós: Introdução e Comentário, pp.260-261; PAUL, S. M. Amos: a Commentary on the Book of Amos, p.281 (formando assim, uma inclusio literária).

${ }^{22}$ Cf. BOVATI, P., MEYNET, R. Il Libro del Profeta Amos, pp.373-374; HUBBARD, D. A. Joel e Amós: Introdução e Comentário, p.260; PAAS, S. Seeing and Singing: Visions and Hymns in the Book of Amos. VT 52 (2002), pp.258-259 e 261; MÖLER, K. 'Hear this Word Against You': a Fresh Look at the Arrangement and the Rhetorical Strategy of the Book of Amos. Vetus Testamentum 50 (2000), p.514; FORESTI, F. Funzione semantica dei brani participiali di Amos: 4,13; 5,8s; 9,5s. Bib 62 (1981), p.183.

${ }^{23}$ Cf. LANG, M., MESSNER, R. Got Erbaut Sein Himmlisches Heiligtum. Zur Bedeutung von in Am 9,6. Bib 82 (2001), pp.94-95; DEMPSTER, S. The Lord is His Name: a Study of the Distribuition of the Names and Titles of God in the Book of Amos. RB 98 (1991), p.184.

${ }^{24}$ Cf. FORESTI, F. Funzione semantica dei brani participiali di Amos: 4,13; 5,8s; 9,5s. Bib 62 (1981), p.178. 


\section{Aspectos teológicos}

\subsection{A imagem de Deus nas doxologias}

a) $\operatorname{Am~4,13~}$

$\mathrm{Na}$ realidade, o v.13 não pertence originalmente à unidade textual de 4,6-13, mas é colocado após os vv.6-12 para lhe dar um novo tom. Desse modo, a unidade pode ser compreendida da seguinte maneira:

- os vv.6-11, como sendo uma revisão histórica do julgamento de YHWH sobre o povo;

- o v.12, o anúncio do julgamento;

- e o v.13, que compõe o clímax da unidade, com a identificação do juiz que instaura o processo contra o povo.

Dessa forma, a doxologia concorda com o seu entorno na medida em que evolui a descrição do julgamento do povo de Israel e desenvolve a seguinte função dentro dessa unidade: exortar ao povo para que volte a Deus, pois o juízo está próximo. Sendo assim, tal doxologia, em sua atual posição, unida aos versículos precedentes, delineia a imagem do Deus criador e onipotente que o povo terá de enfrentar no juízo eminente. ${ }^{25} \mathrm{O}$ v.13, no contexto, além de indicar um louvor ao nome de YHWH reconhecedo assim, a destruição de Israel, apresenta este Deus a quem Israel terá de enfrentar. Assim, tal delimitação seguiria um esquema pedagógico com o objetivo de exortar o povo para o retorno a YHWH, encontrando seu ápice no louvor ao seu nome. ${ }^{26}$

${ }^{25}$ Cf. MCCOMISKEY, T. E. The Minor Prophets: An Exegetical and Expository Commentary. Vol.1: Hosea, Joel and Amos, pp.328 e 407; PAUL, S. M. Amos: a Commentary on the Book of Amos, p.153; BARRÉ, M. L. “Amós”. In: Novo Comentário Bíblico São Jerônimo: Antigo Testamento, pp.443-444; HUBBARD, D. A. Joel e Amós: Introdução e Comentário, pp.137138 e 173-174; BYARGEON, R. W. The Doxologies of Amos: a Study of Their Structure and Theology. TheoEdu 52 (1995), pp.51-53; FORESTI, F. Funzione semantica dei brani participiali di Amos: 4,13; 5,8s; 9,5s. Bib 62 (1981), pp.180-181; DEMPSTER, S. The Lord is His Name: a Study of the Distribuition of the Names and Titles of God in the Book of Amos. $R B 98$ (1991), pp.179-180.

${ }^{26}$ Cf. ZENGER, E. O livro de Amós. In: Introdução ao Antigo Testamento, p.484; JARAMILLO RIVAS, P. “Amós”. In: Comissão Editorial Santiago Guijarro Oporto e Miguel Salvador García. Comentário ao Antigo Testamento. Vol.2, pp.328-329. 
O capítulo 5 é o ponto chave de todo o livro de Amós, não apenas em relação a sua estrutura como também em relação ao seu conteúdo. A dialética morte e vida, relacionada aos temas do direito e do culto, são as características marcantes deste capítulo. A organização estrutural da unidade textual de $5,1-17$, mostra um esquema muito elaborado, tal como: ${ }^{27}$

\begin{tabular}{|c|c|c|c|c|c|}
\hline A & \multicolumn{4}{|c|}{ A temática principal gira em torno da lamentação e morte } & $1-3$ \\
\hline & B & \multicolumn{3}{|r|}{ O tema principal gira em torno da vida: buscar a YHWH } & 4-6 \\
\hline & & $\mathrm{C}$ & & A questão do direito: problemática da injustiça & 7 \\
\hline & & & $\mathbf{D}$ & $\begin{array}{l}\text { Doxologia: aquele que pode gerar a vida ou } \\
\text { a morte (exaltação da imagem de Deus) }\end{array}$ & $8-9$ \\
\hline & & $C^{\prime}$ & & A questão acerca do direito retorna: condenação & 10-13 \\
\hline & B' & \multicolumn{3}{|c|}{ Novamente, o tema da vida é desenvolvido: buscar a YHWH } & 14-15 \\
\hline$A^{\prime}$ & \multicolumn{4}{|c|}{ Volta a ser trabalhada a questão: lamentação e morte } & 16-17 \\
\hline
\end{tabular}

A doxologia de Am 5,8-9 fornece ênfase à perícope, por mostrar o Deus que, ao mesmo tempo, é o Deus que destrói, é também o Deus que dá a vida. Tal afirmação deve ser reconhecida e professada pelo povo. Portanto, assim como Am 4,13, Am 5,8-9, interrompe de forma brusca sua perícope, mas, por outro lado, enfatiza o tema a ser trabalhado. O que está em jogo, nessa unidade, é o contraponto entre vida e morte. A doxologia pode ser vista, então, dentro de sua unidade textual, como uma afirmação majestática da soberania de Deus que, através do impacto cósmico, punirá os responsáveis pelas desigualdades sociais. ${ }^{28}$

${ }^{27}$ Cf. BARRÉ, M. L. “Amós”. In: Novo Comentário Bíblico São Jerônimo: Antigo Testamento, p.444; WOLFF, H. W. La Hora de Amós, pp.55-57; WISDOM, T. A Funeral Dirge for Living (Amos 5,1-9). Bibical Viewpoint 27/2 (1993), pp.17-19; JEREMIAS, J. Amos, pp.110-113; JARAMILLO RIVAS, P. “Amós”. In: Comissão Editorial Santiago Guijarro Oporto e Miguel Salvador García. Comentário ao Antigo Testamento. Vol.2, p.329.

${ }^{28}$ Cf. JEREMIAS, J. Amos, pp.110-113; JARAMILlO RIVAS, P. “Amós”. In: Comissão Editorial Santiago Guijarro Oporto e Miguel Salvador García. Comentário ao Antigo Testamento. Vol.2, p.329. WISDOM, T. A Funeral Dirge for Living (Amos 5,1-9). BView 27/2 (1993), p.21. 
Dentro da unidade textual de Am 9,1-6 a doxologia está ligada ao tema da destruição, consequência do juízo de YHWH, por meio de uma linguagem teofânica.

Na última visão $(9,1-4)$ é relatada a destruição de um templo por meio do abalo sísmico. Esta é a punição estabelecida por YHWH da qual não haverá escapatória. Desse modo, a atual posição da doxologia é proposital. Seu objetivo seria, como conclusão da visão anterior, mostrar que Deus reina em todo o universo e prevalece sobre o tempo e sobre a terra, rejeitando seu povo pecador e afirmando a sua destruição. Desse modo, a quinta visão atinge seu clímax com a afirmação da soberania de YHWH diante toda a obra da criação. ${ }^{29}$

A imagem de Deus delineada nas doxologias transparece em seus textos permeada por uma linguagem específica da tradição sobre a criação. ${ }^{30}$ Tendo em vista a totalidade do projeto de YHWH, este deixa de ser apenas um Deus nacional e passa a ser um Deus universal por ser o criador de tudo e todos, sendo, portanto, o Senhor de toda natureza e, consequentemente, de toda história humana. ${ }^{31}$ Desse modo, YHWH é o Senhor. Assim, pode-se afirmar que todo o livro de Amós tem por objetivo identificar quem deve ser reconhecido como o verdadeiro Deus, Senhor de toda criação.

${ }^{29}$ Cf. SWEENEY, M. A. The Twelve Prophets. Vol.1: Hosea, Joel, Amos, Obadiah, pp.268-271; JEREMIAS, J. Amos, pp.200-202 e 207-209; ZENGER, E. O livro de Amós. In: Introdução ao Antigo Testamento, p.485; SCHWANTES, M. "A Terra não pode suportar suas palavras" (Am 7,10): reflexão e estudo sobre Amós, p.185; HUBBARD, D. A. Joel e Amós: Introdução e Comentário, pp.138, 254-256 e 260-261; HAYES, K. M. The Mourning Earth (Amos 1:2) and the God Who Is. $W \& W 28 / 2$ (2008), p.143; BRAMER, S. J. The Analysis of the Structure of Amos. BSac 156 (1999), p.173; MÖLER, K. 'Hear this Word Against You': a Fresh Look at the Arrangement and the Rhetorical Strategy of the Book of Amos. VT 50 (2000), p.514; FORESTI, F. "Funzione semantica dei brani participiali di Amos: 4,13; 5,8s; 9,5s". In: Bib, 62 (1981), p.183.

${ }^{30} \mathrm{Cf}$. PETERSON, D. L. "The World of Creation in the Book of the Twelve". In: BROWN, W. P., MCBRIDE JR., S. D. God Who Creates: Essays in Honor of W. Sibley Towner, p.207; BYARGEON, R. W. The Doxologies of Amos: a Study of Their Structure and Theology. TheoEdu 52 (1995), p.47.

${ }^{31}$ Cf. SIMIAN-YOFRE, H. Amos: Nueva Versione, Introduzione e Commento, p.202; WOLFF, H. W. La Hora de Amós, p.121; HUBBARD, D. A. Joel e Amós: Introdução e Comentário, pp.124126; STEINMANN, J. O Livro da Consolação de Israel e os Profetas da Volta do Exílio, São Paulo: Paulinas, 1976, p.170 (YHWH teria assim, autoridade para intervir nesta); PFEIFER, G. Das Nachgestellte Erläuternde Partizip - eine Stileigentümlichkeit des Amosbuches. Zeitschrift für Althebräistik 6 (1993), p.236. 
Tais afirmações poderiam responder à problemática dos exilados ao depararem-se com o panteão divino babilônico e suas festividades grandiosas. A própria realidade do exílio apresenta ao povo um novo questionamento: seria Marduk, um dos deuses principais da Babilônia, maior que o Deus YHWH? O próprio deus Marduk possui a imagem de deus criador do mundo e dos seres humanos, e que constrói sua morada no firmamento. Dentro desta nova realidade, YHWH é reconhecido como Deus criador e soberano sobre todas as coisas. No panteão babilônico cada divindade era representada por determinado corpo celeste (por exemplo, as Plêiades e Órion) e nele estabeleceriam sua sede. Mas, ao afirmarem as doxologias que YHWH tem poder sobre os corpos celestes (pois foi ele que os criou), fazem com que eles percam seu sentido mítico (ligado às divindades) e passem a ser vistos como grandes obras de YHWH; por isso, obedecem a suas ordens. Logo, Deus não estabelece mais a sua morada no templo de Jerusalém, mas nas alturas da terra, "construída" por ele próprio. Tudo provém de YHWH, seja a luz ou a escuridão, seja o juízo ou a restauração. Por isso, será frequente, tanto antes como depois do exílio, mostrar os astros e o próprio mundo criado como servis e obedientes à sua vontade.

Neste contexto, as doxologias visam a enfatizar o poder e autoridade daquele que estabelece um juízo contra Israel, sendo este o juiz supremo. Com estas afirmações, mostrarão que YHWH, assim como fica expresso em todo o livro, não tolerará a idolatria ou o culto vazio. Mas, por meio do processo realizado contra Israel, anuncia a sentença como consequência da não conversão do povo: o encontro com o seu Deus. ${ }^{32} \mathrm{O}$ principal inimigo do povo é o próprio povo quando se volta contra o seu Deus. Desse modo, a rejeição de Deus pelo seu povo nasce da prática cultual e social que desemboca e reflete diversas desigualdades. A desgraça anunciada visa o retorno do povo à verdadeira prática da justiça que nasce da prática fiel à aliança. Assim, o anúncio das desgraças parece ter por objetivo alertar o povo para sua correção.

${ }^{32}$ Cf. MCCOMISKEY, T. E., The Minor Prophets: An Exegetical and Expository Commentary. Vol.1: Hosea, Joel and Amos, pp.326, 407 e 483; BARRÉ, M. L. "Amós”. In: Novo Comentário Bíblico São Jerônimo: Antigo Testamento, p.444; BOVATI, P., MEYNET, R. Il Libro del Profeta Amos, p.153; JARAMILLO RIVAS, P. “Amós”. In: Comissão Editorial Santiago Guijarro Oporto e Miguel Salvador García. Comentário ao Antigo Testamento. Vol.2, p.329; PAAS, S. Seeing and Singing: Visions and Hymns in the Book of Amos. VT 52 (2002), p. 274. Segundo Asurmendi, tais doxologias, no contexto do livro, fornecem-lhe uma dimensão universal por tornar amplo seu alcance escatológico (ASURMENDI, J. Amós e Oséias, p.24). 
Como isto não acontece, YHWH deve fazer prevalecer sua ordem, seja ela humana ou cósmica, e assim faz realizar-se a punição. ${ }^{33}$

\subsection{As doxologias e as menções do terremoto}

As doxologias falam de um Deus ligado, sobretudo a fenômenos naturais. Chama a atenção, quanto a isto, que o livro comece mencionando um terremoto $(1,1)$ e que aluda a ele pelo menos em outros dois textos $(8,8$ e 9,1$)$ :

a) Am 1,1: Palavras de Amós, que estava entre os criadores de Técoa. O qual teve uma visão sobre Israel nos dias de Uzias, rei de Judá, e nos dias de Jeroboão, filho de Joás, rei de Israel, dois anos antes do terremoto

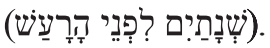

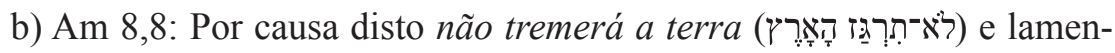

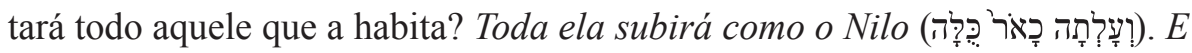

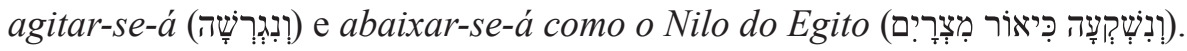

c) Am 9,1: Vi Adonai de pé junto ao altar. Ele disse: "Golpea o capitel, $e$

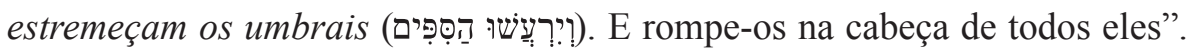
$\mathrm{O}$ resto deles, pela espada matarei. Não fugirá dentre eles aquele que (procura) fugir e não escapará dentre eles o que (procura) escapar.

A imagem do terremoto parece de grande importância para o tema do livro. Ela aparece desde o título até a imagem da destruição do templo de Betel. Tal acontecimento pode ser compreendido, dentro da experiência do povo, como um primeiro passo para a realização do julgamento de YHWH, anunciado por Amós. Tal indicativo traria um "pano de fundo" que só será compreendido em seu último capítulo (como se, no desenrolar da leitura, o leitor desenvolvesse tal visão, tornando-a clara no capítulo 9).

Apesar de no livro encontrarem-se diversas ameaças contra Israel, inclusive o possível exílio (Am 5,27; 6,7), não há referência explícita à Assíria (que impunha a deportação e o exílio aos povos dominados). Ao invés disso, enfatiza-se a imagem de um grande tremor de terra (Am 8,8 e 9,5; cf. 9,1-4), ${ }^{34}$

${ }^{33}$ Cf. LIMA, M. L. C. Am 9,11-15 e a Unidade do Livro dos Doze Profetas. In: Atualidade Teológica 14 (2003), pp.319-324; FRETHEIM, T. E. Creation Untamed: The Bible, God, and Natural Disasters, pp.48-49 (pois as punições são consequências dos crimes cometidos e só YHWH, por meio de seu juízo, pode restabelecer a ordem moral quebrada pelo pecado).

${ }^{34}$ Cf. ANDRADE, A. C. Am 9, 1-4: A dimensão do juízo anunciado e suas motivações à luz de Am 7,1-8,14, p.29. 
além de adversidades no meio rural (Am 7,1-6), como uma consequente punição para o povo em razão dos seus pecados. ${ }^{35}$

Como indicativo de um evento histórico, a menção do terremoto visa ressaltar o mistério da participação do cosmo no julgamento divino, onde Deus tem a iniciativa de assumir, inteiramente, o governo do universo e da história. Nesta perspectiva, é tido como a execução do julgamento divino em consequência do pecado humano. Desse modo, Am 1,1 localiza a atividade profética dois anos antes do terremoto. Já Am 8,8, mostra que o pecado do povo fará a terra tremer, enquanto que Am 9,1 mostra a detruição do templo por meio da imagem do tremor de terra onde não haverá sobreviventes e ninguém escapará. ${ }^{36}$

A referência histórica deste terremoto (ocorrido por volta de 760 a.C.), em particular, em 1,1, pode significar que este foi deveras marcante para que se conservasse na memória do povo (não só dos sobreviventes do Norte, mas, também dos habitantes do Sul). O povo, então, interpretou como sendo uma confirmação das palavras de Amós. ${ }^{37}$ Contudo, este provavelmente não deve ter sido visto como a realização plena das palavras do profeta, mas um indicador primeiro da veracidade de sua atividade, que atingiria seu ponto máximo em uma catástrofe militar. ${ }^{38} \mathrm{~A}$ Assíria só se tornaria uma ameaça a Israel após 745 a.C, com a subida ao trono de Teglat Falasar III, sendo tal acontecimento posterior à atividade profética de Amós no Reino do Norte. ${ }^{39}$ Uma nova leitura de tais acontecimentos ocorrerá após a destruição de Jerusalém. Desse modo, o livro de Amós só teria recebido sua forma final, em época exílica ou pós-exílica. ${ }^{40}$

Portanto, quem está por trás deste desastre é o próprio YHWH. Por ser YHWH o criador, ele estabelece uma ordem harmoniosa no cosmo. Essa ordem, existente na criação, deve refletir-se na história humana por meio da justiça e do direito. A partir do momento em que o ser humano quebra esta

${ }^{35}$ Cf. MCKENZIE, J. L. “Terremoto”. In: Dicionário Bíblico. São Paulo: Paulinas, 1983, p.924.

${ }^{36}$ Cf. MCKENZIE, J. L. "Terremoto". In: Dicionário Bíblico, p.924.

${ }^{37}$ Cf. SCHREINER, J., Palavra e mensagem do Antigo Testamento, p.172.

${ }^{38}$ Cf. BOVATI, P., MEYNET, R., Il Libro del Profeta Amos, p.36; SICRE DIAZ, J. L., Profetismo em Israel: o profeta, os profetas, a mensagem, p.249; HUBBARD, D. A. Joel e Amós: Introdução e Comentário, p.124.

${ }^{39}$ Cf. SWEENEY, M. A. The Twelve Prophets. Vol.1: Hosea, Joel, Amos, Obadiah, p.194; MCCOMISKEY, T. E., The Minor Prophets: An Exegetical and Expository Commentary. Vol.1: Hosea, Joel and Amos, pp.319-321; SIMIAN-YOFRE, H., Amos: Nueva Versione, Introduzione e Commento, p.32.

${ }^{40}$ Cf. JEREMIAS, J. Amos, pp.15-16. 
ordem estabelecida por Deus, colocando em prática injustiças e desigualdades, Deus pode quebrar a ordem do cosmo, por meio dos desastres naturais, tal como o terremoto, para alertar e fazer o ser humano retornar a ordem estabelecida por ele.

\section{Conclusão}

Vê-se assim, no estudo das doxologias do livro de Amós, que, por trás da imagem do terremoto, os fenômenos naturais são obras da ação de YHWH dentro da história humana. A imagem do terremoto, então, parece de grande importância para o tema do livro de Amós. No sentido religioso, o terremoto pode ser compreendido como a intervenção divina na natureza, associada, principalmente, a cólera e a ameaça divina. Pode indicar, também, a presença de Deus no meio do seu povo.

Desse modo, no contexto de julgamento, a execução do juízo divino em consequência do pecado humano ocorre devido ao fato de que, na obra criada, há uma ordem equitativa estabelecida por YHWH que deve refletir-se na vida humana. A partir do momento em que o ser humano quebra a ordem estabelecida por YHWH, YHWH pode alterar a ordem cósmica, usando, por exemplo, um terremoto, para fazer o ser humano retornar á ordem estabelecida por ele. Sendo assim, a imagem do tremor de terra, em Amós, está associada ao juízo em vista do pecado social e cúltico de Israel, para que haja uma mudança imediata em Israel, assim como acontecerá com a terra: Israel deve retornar à ordem da justiça e do direito.

\section{Referências Bibliográficas}

ABREGO DE LACY, J. M. Os livros proféticos. São Paulo: Ave-Maria, 1998. ALONSO SCHÖKEL, L. Dicionário Bíblico Hebraico-Português. São Paulo: Paulus, 1997.

. SICRE DIAZ, J. L., Profetas. Vol.2. São Paulo: Paulinas, 1991, pp.981-1024.

ANDRADE, A. C. Am 9, 1-4: A dimensão do juízo anunciado e suas motivações à luz de Am 7,1-8,14. Rio de Janeiro: PUC, Departamento de Teologia, Dissertação de Mestrado, 2003.

ASURMENDI, J. Amós e Oséias. São Paulo: Paulinas, 1992. 
BALLARINI, T., VIRGULIN, S., LYONNET, S. Introdução à Bíblia: com antologia profética. Vol.2. Petrópolis, RJ: Vozes, 1978.

BARRE, M. L. “Amós”. In: Novo Comentário Bíblico São Jerônimo: Antigo Testamento. São Paulo: Academia Cristã Ltda., Paulus, 2007, pp.437-449.

BOVATI, P., MEYNET, R. Il Libro del Profeta Amos. Roma: Edizione Dehoniane, 1995.

BRAMER, S. J. The Analysis of the Structure of Amos. Bibliotheca Sacra 156 (1999), pp.160-174.

BYARGEON, R. W. The Doxologies of Amos: a Study of Their Structure and Theology. Theological Educator 52 (1995), pp.47-56.

DEMPSTER, S. The Lord is His Name: a Study of the Distribuition of the Names and Titles of God in the Book of Amos. Revue Biblique 98 (1991), pp.170-189.

EICHRODT, W. Teologia do Antigo Testamento. São Paulo: Hagnos, 2004.

FORESTI, F. Funzione semantica dei brani participiali di Amos: 4,13; 5,8s; 9,5s. Biblica 62 (1981), pp.169-184.

FRETHEIM, T. E. Creation Untamed: The Bible, God, and Natural Disasters. Theological Exploration for the Church Catholic; Grand Rapids, Ml: Baker Academic, 2010.

HASEL, G. F. Understanding the Book of Amos: Basic Issues in Current Interpretations. Grand Rapids: Baker, 1991.

HAYES, K. M. The Mourning Earth (Amos 1:2) and the God Who Is. Word \& World 28/2 (2008), pp.141-149.

HUBBARD, D. A. Joel e Amós: Introdução e Comentário. São Paulo: Vida Nova, 1996.

JARAMILLO RIVAS, P. “Amós". In: Comissão Editorial Santiago Guijarro Oporto e Miguel Salvador García. Comentário ao Antigo Testamento. Vol.2. São Paulo: Ave Maria, 2004, pp.323-333.

JEREMIAS, J. Amos. Brescia: Paidéia Edritice, 2000.

LANG, M., MESSNER, R. Got Erbaut Sein Himmlisches Heiligtum. Zur Bedeutung von אגדתו in Am 9,6. Biblica 82 (2001), pp.93-98. 
LIMA, M. L. C. Am 9,11-15 e a Unidade do Livro dos Doze Profetas. Atualidade Teológica 14 (2003), pp.182-199.

MCCOMISKEY, T. E. The Minor Prophets: An Exegetical and Expository Commentary. Vol.1: Hosea, Joel and Amos. Baker Book House: Grand Rapids, Michigan 49516, 1992.

MCKENZIE, J. L. "Terremoto". Dicionário Bíblico. São Paulo: Paulinas, 1983, p.924.

MÖLER, K. 'Hear this Word Against You': a Fresh Look at the Arrangement and the Rhetorical Strategy of the Book of Amos. Vetus Testamentum 50 (2000), pp.499-518.

PAAS, S. Seeing and Singing: Visions and Hymns in the Book of Amos. Vetus Testamentum 52 (2002), pp.253-274.

PAUL, S. M. Amos: a Commentary on the Book of Amos. Minneapolis: Fortress Press, 1991.

PETERSON, D. L. "The World of Creation in the Book of the Twelve". In: BROWN, W. P., MCBRIDE JR., S. D. (eds.)., God Who Creates: Essays in Honor of $W$. Sibley Towner. Grand Rapids, Ml/Cambridge, U.K.: Eerdmans, 2000, pp.204-214.

PFEIFER, G. Das NachgestellteErläuterndePartizip-eine Stileigentümlichkeit des Amosbuches. Zeitschrift für Althebräistik 6 (1993), pp.235-238.

SCHWANTES, M. "A Terra não pode suportar suas palavras" (Am 7,10): reflexão e estudo sobre Amós. São Paulo: Paulinas, 2004.

SICRE DIAZ, J. L. Profetismo em Israel: o profeta, os profetas, a mensagem. Petrópolis, RJ: Vozes, 1996.

SIMIAN-YOFRE, H. Amos: Nueva Versione, Introduzione e Commento. Milan: Paoline, 2002.

STEINMANN, J. O Livro da Consolação de Israel e os Profetas da Volta do Exílio. São Paulo: Paulinas, 1976.

SWEENEY, M. A. The Twelve Prophets. Vol.1: Hosea, Joel, Amos, Obadiah, Jonah. A. Michael Glazier Book: Collegeville, MN: Liturgical Press, 2000 . 
VON RAD, G. Teologia do Antigo Testamento. Vol. 1 e 2. São Paulo: ASTE/ TARGUMIM, 2006.

WAARD, J. The Chiastic Structure of Amos V 1-17. Vetus Testamentum 27 (1977), pp.170-177.

WISDOM, T. A Funeral Dirge for Living (Amos 5,1-9). Biblical Viewpoint 27/2 (1993), pp.17-22.

WOLFF, H. W. La Hora de Amós. Salamanca: Ediciones Sígueme, 1984.

ZENGER, E. "O livro de Amós". In: Introdução ao Antigo Testamento. São Paulo: Loyola, 2003, pp.480-492.

\section{Mariana do Nascimento Pernambuco Mestre em Teologia Bíblica pela PUC-Rio Rio de Janeiro/RJ - Brasil E-mail: marianapernambuco3@gmail.com}

Recebido em: 01/06/13 Aprovado em: 26/05/14 